\title{
EFFECTS OF VISUAL DISTRACTION ON REACTION TIME IN A SIMULATED TRAFFIC ENVIRONMENT
}

C. JOSH HOLAHAN

RESEARCH REPORT 47

MARCH 1977

TEXAS OFFICE OF TRAFFIC SAFETY

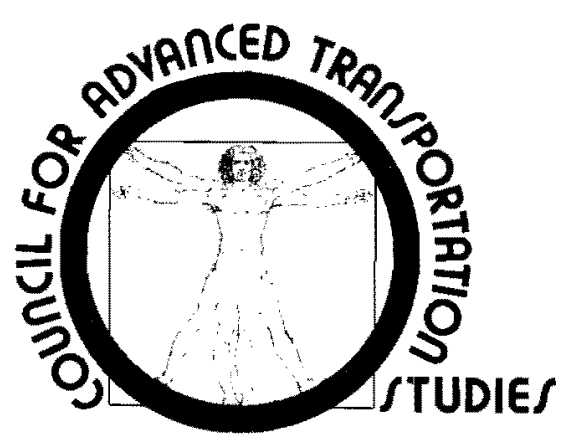


1 An Integrated Methodology for Estimating Demand for Essential Services with an Application to Hospital Care. Ronald Briggs, Wayne T. Enders, James Fitzsimmons, and Paul Jensen, April 1974 (DOT-TST-75-81).

2 Transportation Impact Studies: A Review with Emphasis on Rural Areas. Lidvard Skorpa, Richard Dodge, C. Michael Walton, and John Huddleston, October 1974 (DOT-TST-75-59).

4 Inventory of Freight Transportation in the Southwest/Part I: Major Users of Transportation in the Dallas-Fort Worth Area. Eugene Robinson, December 1973 (DOT-TST-75-29).

5 Inventory of Freight Transportation in the Southwest/Part II: Motor Common Carrier Service in the Dallas-Fort Worth Area. I. Bryan Adair and James S. Wilson, December 1973 (DOT-TST-75-30).

6 Inventory of Freight Transportation in the Southwest/Part III: Air Freight Service in the Dallas-Fort Worth Area. I. Bryan Adair, June 1974 (DOT-TST-75-31).

7 Political Decision Processes, Transportation Investment and Changes in Urban Land Use: A Selective Bibliography with Particular Reference to Airports and Highways. William D. Chipman, Harry P. Wolfe, and Pat Burnett, March 1974 (DOT-TST-75-28).

9 Dissemination of Information to Increase Use of Austin Mass Transit: A Preliminary Study. Gene Burd, October 1973.

10 The University of Texas at Austin: A Campus Transportation Survey. Sandra Rosenbloom, Jane Sentilles Greig, and Lawrence Sullivan Ross, August 1973.

11 Carpoof and Bus Matching Programs for The University of Texas at Austin. Sandra Rosenbloom and Nancy Shelton Bauer, September 1974.

12 A Pavement Design and Management System for Forest Service Roads: A Conceptual Study. W. R. Hudson and Thomas G. McGarragh, July 1974.

13 Measurement of Roadway Roughness and Motion Spectra for the Automobile Highway System. Randall Bolding, Anthony Healey, and Ronald Stearman, December 1974.

14 Dynamic Modeling for Automobile Acceleration Response and Ride Quality Over Rough Roadways. Anthony Healey, Craig C. Smith, Ronald Stearman, and Edward Nathman, December 1974.

15 Survey of Ground Transportation Patterns at the Dallas-Fort Worth Regional Airport. William I. Dunlay, Jr., Thomas G. Caffery, Lyndon Henry, and Douglas Wiersig, August 1975.

16 The Prediction of Passenger Riding Comfort from Acceleration Data. Craig C. Smith, David Y. McGehee, and Anthony J. Healey, March 1976.

17 The Transportation Problems of the Mentally Retarded, Shane Davies and John W. Carley, December 1974.

18 Transportation-Related Constructs of Activity Spaces of Small Town Residents. Pat Burnett, John Betak, David Chang, Wayne Enders, and Jose Montemayor, December 1974 (DOT-TST-75-135).

19 Marketing of Public Transportation: Method and Application. Mark I. Alpert and Shane Davies, January 1975.

20 The Problems of Implementing a 911 Emergency Telephone Number System in a Rural Region. Ronald T. Matthews, February 1975.

23 Forecast of Truckload Freight of Class / Motor Carriers of Property. Mary Lee Corse, March 1975 (DOT-TST-75-138).

24 Forecast of Revenue Freight Carried by Rail in Texas to 1990. David L. Williams, April 1975 (DOT-TST-75-139).

28 Pupil Transportation in Texas. Ronald Briggs, Kelly Hamby, and David Venhuizen, July 1975.

30 Passenger Response to Random Vibration in Transportation Vehicles. Anthony J. Healey, June 1975.

35 Perceived Environmental Utility under Alternative Transportation Systems: A Framework for Analysis. Pat Burnett, March 1976.

36 Monitoring the Effects of the Dallas/Fort Worth Regional Airport. Volume I: Ground Transportation Impacts. William J. Dunlay,

Ir., Thomas G. Caffery, Lyndon Henry, Douglas W. Wiersig, and Waldo Zambrano, December 1976.

37 Monitoring the Effects of the Dallas/Fort Worth Regional Airport. Volume 1I: Land Use and Travel Behavior. Pat Burnett, David Chang, Carl Gregory, Arthur Friedman, Jose Montemayor, and Donna Prestwood, July 1976.

38 Transportation and Community Development-A Manual for Small Communities: Level I, Volume I-Executive Summary; Volume II-The Planning Process. Richard Dodge, John Betak, C. Michael Walton, Charles Heimsath, and John Huddleston, July 1976 .

39 An Evaluation of Promotional Tactics and Utility Measurement Methods for Public Transportation Systems. Mark Alpert, Linda Colden, John Betak, James Story, and C. Shane Davies, March 1977.

40 A Survey of Longitudinal Acceleration Comfort Studies in Ground Transportation Vehicles. L. L. Hoberock, July 1976.

41 Lateral Steering Dynamics Model for the Dallas/Fort Worth AIRTRANS. Craig C. Smith, December 1976 (Draft Report).

42 Guideway Sidewall Roughness and Guidewheel Spring Compressions of the Dallas/Fort Worth AIRTRANS. William R. Murray and Craig C. Smith, August 1976 (Draft Report).

43 A Pavement Design and Management System for Forest Service Roads: A Working Model. Freddy L. Roberts, B. Frank McCullough, Hugh J. Williamson, William R. Wallin, February 1977.

44 A Tandem-Queue Algorithm for Evaluation of Overall Airport Capacity. Chang-Ho Park, April 1977 (Draft Report).

45 Characteristics of Local Passenger Transportation in Texas. Ronald Briggs, January 1977 (Draft Report). 
EFFECTS OF VISUAL DISTRACTION ON REACTION TIME IN

A SIMULATED TRAFFIC ENVIRONMENT

\author{
C. Josh Holahan
}

March 1977

Research Report 47

Prepared by

Council for Advanced Transportation Studies

The Universtty of Texas at Austin Austin, Texas 78712

For

Texas Office of Traffic Safety

State Department of Highways and Public Transportation Austin, Texas 
This report was developed by the Councll for Advanced Transportation Studies in cooperation with the Texas office of Traffic Safety in the interest of information exchange. 
Techaicol Repont Documantation Page

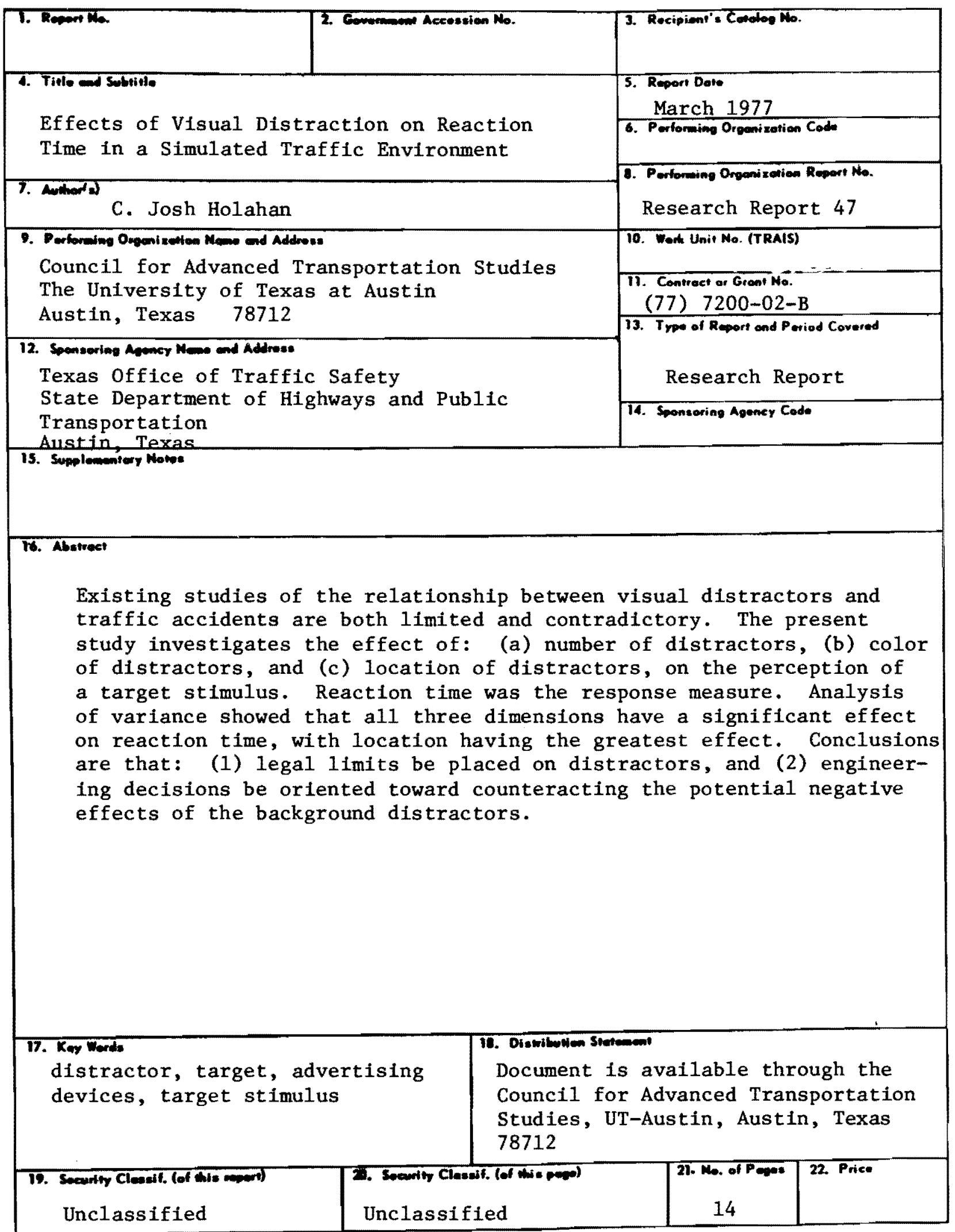


At the present time, the relationship between commercial signs (visual distractors) and traffic safety must be based on limited and contradictory research findings. Some studies have shown a positive correlation between both the presence of advertising devices and the number of elements in the roadside environment, and traffic accidents. Other research has found no relationship between adverising signs and highway accidents. Controlled laboratory experiments provide little more information.

The present study investigates the effect of: (a) the number of distractors $(2,4,6$, or 10), (b) the color of distractors (six combinations of red, orange, and the cool colors of blue, green and black), and (c) the location of distractors (proximate or distant), on the perception of a target stimulus (stop sign). Reaction time in responding to the target stimulus was the response measure.

Subjects were 56 Introductory Psychology students (29 males). Each subject responded to 96 stimulus pictures, presented on an 18 " by $12^{\prime \prime}$ screen, by depressing "stop" or "go" buttons, depending on the presence or absence of the target stimulus. The 96 pictures represented pairs of the 48 possible combinations of the three dimensions under study, one with the target stimulus and one without. Presentation of the slides and measurement of the reaction times were controlled by a PDP 8 computer.

A 4 by 6 by 2 analysis of variance with reaction time as the dependent variable showed statistically significant main effects and both two-way and three-way interaction effects. Of the three dimensions under study, proximity was found to have the greatest effect on reaction times. This suggests that the dominant process was the subject's inability to discriminate figure from ground.

In general, these results suggest that: (1) appropriate ordinances be established to legislatively limit the effect of distractors, and (2) that engineering decisions involving design changes in the target signal be oriented toward counteracting the potential negative effects of the background distractors. 
TABLE OF CONTENTS

Page

Executive Summary . . . . . . . . . . . . . . . . . .

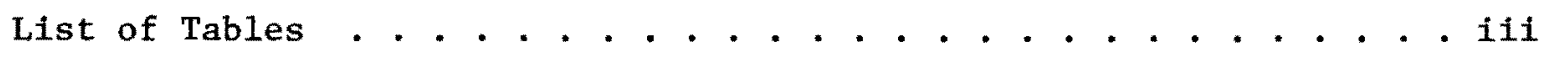

Method . . . . . . . . . . . . . . . . . . . 3

Results and Discussion . . . . . . . . . . . . . . . . 6

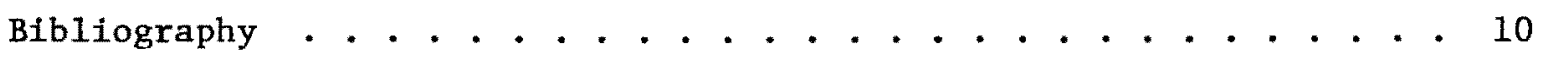

Biographical Sketch . . . . . . . . . . . . . . . . . 11 


\section{LIST OF TABLES}

PAGE

TABLE 1. Summary of Three-Factor Analysis of Variance (Number of Distractors X Color X Location)

With Reaction Time as Dependent Variable . . . . . . . 6

TABLE 2. Mean Reaction Times for Number and Color of Distractors Broken Down by Location . . . . . . . . . 8

TABLE 3. Mean Reaction Times for Number of Distractors Broken Down by Color . . . . . . . . . . . . . 8 
EFFECTS OF VISUAL DISTRACTION ON REACTION TIME IN

A SMUULATED TRAFF IC ENV IRONMENT

The character of commercial development in many urban and suburban areas has resulted in a plethora of advertising signs, neon lights, and gaudy b111boards amassed along the roadside environment. While some recent studies 1 have attempted to evaluate the Impact of such development from an essentially aesthetic perspective, surprisingly 11ttle research has examined the relationship between this array of potential visual distractors in the roadside environment and traffic safety. As part of a program to identify potentially effective traffic safery countermeasures, it was decided that a study should be developed to evaluate the effect of background visual distractors due to commerical development. on human performance associated with traffic safety.

Although ordinances exist in most local communities which regulate the placement, size, and light intensity of commercial signs, such regulations are often very vague. One local regulation, for example, prohibits "any change in light intensity, motion, or color which subconsclously fixates or attracts the eyes of the motorist when they should be driving." 2 Typically, these ordinances are written by policy makers whose decisions are based not on actual traffic safety evidence, but rather on personal intuition. Shoaf describes how traffic managers in San Francisco developed an elaborate, restrictive policy for the placement of advertising signs near freeways, while acknowledging that the evidence relating such signs to highway accidents remained inconclusive. ${ }^{3}$

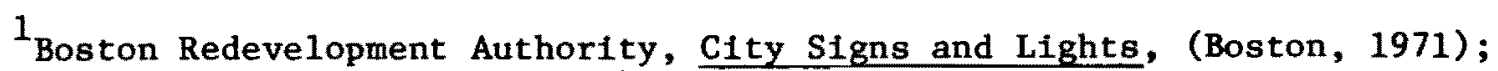
G. Winkel, R. Malek and P. Th1el, "Community Response to the Design Features of Roads: A Technique for Measurement," Highway Research Record, 305 (1970), pp. 133-145.

2R. T. Shoaf, "Are Advertising Signs Near Freeways Traffic Hazards?," Traffic Engineer, 26, No. 2 (1955), pp. 74.

${ }^{3}$ Ibid. 
Very little inquiry has been directed toward visual distractors and traffic accidents in field settings, and those data that do exist are both contradictory and open to methodological criticism. Two studies ${ }^{4}$ have reported positive correlations between the presence of advertising devices and automobile accidents on multilane highways. In addition, two studies ${ }^{5}$ have indicated a positive relationship between traffic accidents and the number of elements in the roadside environment, such as commercial establishments, intersections, driveways, and traffic signals. Other evidence, ${ }^{6}$ however, has reported no relationship between highway accidents and advertising signs.

In contrast, while a large body of research in a controlled experimental format has examined perception of the target traffic stimulus, ${ }^{7}$ e.g., the color, size and lettering of road signs, almost no inquiry has systematically investigated perception of the target traffic signa1 as a function of distractors in its environmental background. Thus, while traffic engineers possess considerable knowledge relevant to the construction of adequate traffic signs isolated from their environmental context, very little is known about how to evaluate features of the background environment which may contribute to or reduce road sign effectiveness. An exception is a recent laboratory study

${ }^{4}$ Madigan-Hyland, Inc., Signs and Accidents on New York State Thruway, Report prepared for the New York State Thruway Authority, February 1963; Minnesota Department of Highways, Minnesota Rura1 Trunk Highway Accident, Access Point, and Advertising Sign Study, (Minneapolis: 1952).

${ }^{5}$ J. A. Head, "Predicting Traffic Accidents from Elements on Urban Extensions of State Highways," Highway Research Board Bulletin, 208 (1959), pp. 45-63; J. Versace, "Factor Analysis of Roadway and Accident Data," Highway Research Board Bulletin, 240 (1960), pp. 24-30.

6. C. McMonagle, "Traffic Accidents and Roadside Features," Highway Research Board Bulletin, 55 (1952), pp. 38-48; J. C. McMonagle, "The Effects of Roadside Features on Traffic Accidents," Traffic Quarter1y, 6, No. 2 (1952), pp. 228-243.

${ }^{7}$ T. W. Forbes, "Factors in Highway Sign Visibility," Traffic Engineering, 39 (1969), pp. 20-27; T. W. Forbes, T. E. Snyder and R. F. Pain, "Traffic Sign Requirements I: Review of Factors Involved, Previous Studies and Needed Research," Highway Research Record, 70 (1965), pp. 48-56. 
of distraction by irrelevant information, ${ }^{8}$ which lends partial support to the contention that such distractors reduce driving performance under high information load conditions. In addition, Kahneman, Ben-Ishai, and Lotan ${ }^{9}$ afford some Indirect evidence, utilizing a selective attention task with bus drivers, demonstrating an inverse correlation between task performance and traffic accident history.

The purpose of the present study was to systematically examine the effect of manipulations along a number of specific dimensions in the background environment on reaction time in responding to a target traffic stimulus, using a controlled experimental simulation of a traffic environment. The dimensions of the background environment investigated were selected both on the basis of the results of the small number of available field studies and on the probability of affording applicable information to traffic engineers. The background dimensions studied were: (1) number of distractors, (2) color of distractors, and (3) location of distractors relative to the target stimulus. Reaction time in responding to the target signal was selected as the response measure because it was assumed to relate to both attentional deficits and accident risk in real driving situations. A controlled experimental format was chosen to afford the type of unequivocal data previously lacking in this area of investigation. It was hypothesized that increasing numbers of distractors, greater similarity of color between distractors and target, and closer proximity of distractors to the target would all exert significant increases in reaction time.

METHOD

Subjects

Subjects were 56 Introductory Psychology students who fulfilled a course requirement by their participation in the study. The sample included 29 males and 27 females.

${ }^{8}$ A. W. Johnston and B. L. Cole, "Investigations of Distraction by Irrelevant Information," Australian Road Research, 6, No. 3 (1976), pp. 3-23.

9 D. Kahneman, Ben-Isha1, and M. Lotan, "Relation of a Test of Attention to Road Accidents," Journal of Applied Psychology, 58, No. 1 (1973), pp. 113115 . 


\section{Apparatus}

Target and distractor stimuli. The target trafflc stimulus consisted of an octagonal 2-1nch $(5.08 \mathrm{~cm}$. dlagonal measure) replica of a standard traffic stop sign with white lettering on a red background. The background distractors consisted of $13 / 4$-inch $(4.45 \mathrm{~cm}$.) square replicas of comnercial signs with white lettering on solid backgrounds of five colors (red, orange, blue, green, and black). A different four-letter word was printed on each distracting sign; the words were chosen from Kucera and Francis ${ }^{10}$ to have a moderately high English language occurrence. The differential shapes of the target and distractors were chosen to simulate the situation in the actual traffic environment where a stop sign's octagonal shape is typically contrasted with rectangular commercial signs.

Visual displays. The visual displays were constructed through photographic slides of the target in a number of contrasting distractor backgrounds. The field behind the target and distractors was pale blue, simulating the sky color against which such stimuli are often perceived in the actual environment. The manupulations of the background environment were operationalized as follows;

(1) Number of Distractors - the number of distractors were 2, 4, 6, and 10.

(2) Color of Distractors - the color of the distractors was defined as the color of the sign's background, and included either high similarity to the target (red), intermediate similarity (orange), or low similarity (cool colors of blue, green, or black). This dimension was varied by altering the color combinations of distractors as follows: all red, all orange, all cool, combined red and orange, combined red and cool, combined orange and cool.

(3) Location of Distractors - the locations of the distractors were either proximate to the target or distant from the target. The distinction between proximate and distant was operationalized by dividing the field into a $7 \times 5$ grid (the grid was not visible on the slides) of 2 inch $(5.08 \mathrm{~cm}$.) squares. Under the proximate condition, no distractor was further than $41 / 2$ inches $(11.4 \mathrm{~cm}$.) from the target; distractors were randomly placed within this range. Under the distant condition, no distractor was closer than $41 / 2$ inches $(11.4 \mathrm{~cm}$.) to the target; distractors were randomly placed within this range.

${ }^{10} \mathrm{H}$. Kucera and W. N. Francis, Computational Analysis of Present-Day American English, (Providence, R.I.: Brown University Press, 1967). 
Three distractor dimensions were crossed, resulting in a total of 48 distractor combinations.

Slide presentation. The subject sat facing an $18-i n c h(45.72 \mathrm{~cm}$.) by 12 -inch $(30.48 \mathrm{~cm}$.$) frosted glass panel approximately three feet (.91 \mathrm{~m}$.) away on which stimulus slides were projected from behind by a Kodak Carousel slide projector. A PDP8 computer was used to coordinate the slide presentations and to measure and record reaction time in milliseconds to each presentation. A table immediately in front of the subject held a console (connected to the PDP8) with two buttons, labeled either "stop" or "go."

\section{Procedure}

Subjects were tested singly. Each subject was presented a sequence of 106 slides. The slides consisted of 48 pairs of distractor combinations, one with the target stop sign present and one with the stop sign absent. In addition, ten initial practice slides were presented to familiarize the subject with the equipment. Following the ten practice slides, the order of presentation for the slides was randomized. The following verbal instructions were presented to each subject:

You will see a series of slides on the screen in front of you. While all of the slides will contain some square signs, some slides will contain, in addition, a replica of an ordinary traffic stop sign. If a stop sign is present, press the button on your left/right with your left/right forefinger. If no stop sign is present, press the button on your right/left with your right/left forefinger. You are to react as quickly as you can, while also attempting to avoid mistakes.

Subjects responded using the forefingers of their right and left hands. For half of the subjects the "stop" button was placed on the right, and for half of the subjects it was placed on the left. Each slide remained on until either the subject responded or 1.5 seconds had elapsed. A one-second intertrial interval preceded the presentation of the next slide. Errors were eliminated from the analysis. (Errors constituted only two percent of responses, and their pattern approximated the reaction time curve of correct responses.) 
RESULTS AND DISCUSSION

Table 1 presents the results of a 4 by 6 by 2 analysis of variance (number by color by location) with reaction time as the dependent variable.* These results strongly support the proposed hypotheses. Number, color, and location showed statistically significant $(\alpha=.01)$ main effects, with increasing number of distractors, greater similarity in color between distractors and target, and closer proximity of distractors to target all demonstrating positive relationships to reaction time. In addition, all two-way and three-way interactions were statistically significant.

TABLE 1

SUMMARY OF THREE-FACTOR ANALYSIS OF VARIANCE

(NUMBER OF DISTRACTORS X COLOR X LOCATION)

WITH REACTION TIME AS DEPENDENT VARTABLE

\begin{tabular}{|c|c|c|c|}
\hline SOURCE & df & $\mathrm{F}$ & $\mathrm{p}$ \\
\hline A (Number) & 3 & 14.63 & .0001 \\
\hline B (Color) & 5 & 6.26 & .0001 \\
\hline C (Location) & 1 & 52.00 & .0001 \\
\hline$A \times B$ & 15 & 9.93 & .0001 \\
\hline$A \times C$ & 3 & 5.57 & .0012 \\
\hline$B \times C$ & 5 & 5.47 & .0002 \\
\hline$A \times B \times C$ & 15 & 9.57 & .0001 \\
\hline
\end{tabular}

Mean reaction times for the number dimension were: 2 (587.56 ms.), 4 (588.84 ms.), 6 (611.38 ms.), and 10 (616.28 ms.). Interestingly, this curve reflects a nonlinear function, with a step-wise increase in reaction time occurring between 4 and 6 distractors. For the color dimension, mean reaction times in order of increasing magnitude were: all orange (581.65 ms.), combination of orange and $\operatorname{cool}$ (595.06 ms.), all cool (600.72 ms.), combination of red and cool (602.07 ms.), all red (612.04 ms.), and combination of

* The analysis is limited to the slide presentations where the stop sign target was present. A separate analysis of the slides where the target was absent revealed a similar pattern of responses. 
red and orange (614.57 ms.). Although this effect is complex, the dominant factor in affecting reaction time is the presence of at least some red distractors. Mean reaction times for the location dimension were: distant (586.93 ms.) and proximate (615.10 ms.).

The two-way interactions between the background dimensions were especially interesting. Table 2 shows mean reaction times for number by location and color by location. All proximate distractors yielded high reaction times, while distant distractors reflected differential effects due to both number and color of distractors. Table 3 shows mean reaction times for number by color. While this interaction is complex, it appears that when some red distractors are present, reaction times are highly independent of the number of distractors, while with no red distractors, reaction time varies as a function of number of distractors.

Based on these interactional findings, it is possible to offer some speculation concerning underlying psychological processes that may have mediated the effects of background distractors on reaction time in this study. The overwhelmingly strong effect due to proximity indicates that the dominant process was the subject's inability to discriminate figure (target stop signal) from ground (array of background distractors). The failure of either number or color to appreciably affect reaction time in the proximate condition suggests that this figure-ground separation operated as a gestalt, rather than a sequential screening of each distracting element. In contrast, the strong effects due to both number and color under the distant arrangement may indicate that here the subject reverted to an alternative process involving a visual scanning of the discrete distracting elements.

In light of these results, a number of practical suggestions may be offered to traffic engineers concerned with minimizing the potential negative effects of background distractors in the traffic environment. Most importantly, the present findings underscore the need for the traffic engineer to accept broader legislative and engineering responsibility for the total traffic environment, including both the public roadway and the contingent environmental context. In general, such feedback falls under two areas of application: (1) the establishment of appropriate ordinances to legislatively limit the effect of distractors, and (2) engineering decisions involving design changes in the target signal oriented toward counteracting the potential negative 
TABLE 2

MEAN REACTION TIMES

FOR NUMBER AND COLOR OF DISTRACTORS

BROKEN DOWN BY LOCATION

\begin{tabular}{|c|c|c|c|c|c|c|}
\hline \multirow[t]{2}{*}{ LOCATION } & & \multicolumn{4}{|c|}{ NUMBER } & \\
\hline & & $\underline{2}$ & $\underline{4}$ & $\underline{6}$ & $\underline{10}$ & \\
\hline Distant & & 564.16 & 568.23 & 605.13 & 610.21 & \\
\hline \multirow[t]{3}{*}{ Proximate } & & 610.97 & 609.46 & 617.64 & 622.35 & \\
\hline & \multicolumn{6}{|c|}{ COLOR } \\
\hline & $\begin{array}{c}\text { A11 } \\
\text { Orange } \\
\end{array}$ & $\begin{array}{l}\text { Orange } \\
\& \text { Cool } \\
\end{array}$ & $\begin{array}{l}\text { Al1 } \\
\text { Cool } \\
\end{array}$ & $\begin{array}{r}\text { Red \& } \\
\text { Cool } \\
\end{array}$ & $\begin{array}{l}\text { Al1 } \\
\text { Red }\end{array}$ & $\begin{array}{l}\text { Red \& } \\
\text { Orange } \\
\end{array}$ \\
\hline Distant & 556.85 & 579.66 & 573.19 & 587.96 & 609.27 & 614.67 \\
\hline Proximate & 606.45 & 610.47 & 628.25 & 616.18 & 614.81 & 614.46 \\
\hline
\end{tabular}

TABLE 3

MEAN REACTION TIMES FOR NUMBER OF DISTRACTORS BROKEN DOWN BY COLOR

\begin{tabular}{ccc}
\hline NUMBER & \multicolumn{2}{c}{ COLOR } \\
\cline { 2 - 3 } & $\begin{array}{c}\text { No Red } \\
\text { Distractors }\end{array}$ & $\begin{array}{c}\text { Some Red } \\
\text { Distractors }\end{array}$ \\
\hline 4 & 563.60 & 611.53 \\
6 & 582.32 & 595.37 \\
10 & 618.35 & 604.41 \\
& 605.63 & 626.93 \\
\hline
\end{tabular}


effects of background distractors.

The particularly strong effects in the present study relating to figureground discrimination, suggest that the location of distractors relative to the target signal is of paramount importance. Any number or color of distractors located proximally to the target are likely to reduce the driver's ability to effectively discriminate a target traffic device. Where proximate distractors cannot be legislatively restricted, a wider range of engineering alternatives may be needed to counteract their potentially serious effects. Such developments might involve designing larger or brighter target signals or employing neutral background shields to more effectively contrast the target with its surrounding context. The present findings pertaining to visually scanning the environmental field, support the need for appropriately restrictive legislation relevant to more distant commercial stimuli, which due to either their high number or simflarity in color to traffic regulatory devices may operate as potential traffic hazards.

clearly, the present study represents only a first step in a complex sphere of investigation. Caution needs to be exercised in generalizing these findings in a controlled laboratory arrangement to the problem of roadside distractors in the natural environment. Further research is needed to demonstrate that the type of differences in reaction time found here relate to actual traffic accidents. In fact, under a continued contract with the Texas office of Traffic Safety, we are inftiating a field study investigating the relationship between these distractor dimensions identified as important in the laboratory and traffic accidents in the natural environment. This type of research is especially important as $1 \mathrm{t}$ is apparent that established traffic research knowledge, traditional engineering alternatives, and existing environmental legislation may be inadequate for coping effectively with the burgeoning visual complexity of the contemporary environmental scene. 


\section{BIBLIOGRAPHY}

Boston Redevelopment Authority. City Signs and Lights. Boston: 1971.

Forbes, T. W. "Factors in Highway Sign Visibility." Traffic Engineering, 39 (1969), pp. 20-27.

Forbes, T. W., T. E. Snyder and R. F. Pain. "Traffic Sign Requirements I: Review of Factors Involved, Previous Studies and Needed Research." Highway Research Record, 70 (1965), pp. 48-56.

Head, J. A. "Predicting Traffic Accidents from Elements on Urban Extensions of State Highways." Highway Research Board Bulletin, 208 (1959), pp. 45-63.

Johnston, A. W. and B. L. Cole. "Investigations of Distraction by Irrelevant Information." Australian Road Research, 6 (1976), pp. 3-23.

Kahneman, D., R. Ben-Ishai and M. Lotan. "Relation of a Test of Attention to Road Accidents." Journal of Applied Psychology, 58 (1973), pp. 113-115.

Kucera, H. and W. N. Francix. Computational Analysis of Present-Day American English. Providence: Brown University Press, 1967.

Madigan-Hyland, Inc. Signs and Accidents on New York State Thruway. Report prepared for the New York State Thruway Authority, February, 1963.

McMonagle, J. C. "Traffic Accidents and Roadside Features." Highway Research Board Bulletin, 55 (1952), pp. 38-48.

McMonagle, J. C. "The Effects of Roadside Features on Traffic Accidents." Traffic Quarter1y, 6 (1952), pp. 228-243.

Minnesota Department of Highways. Minnesota Rural Trunk Highway Accident, Access Point, and Advertising Sign Study. Minneapolis: 1952.

Shoaf, R. T. "Are Advertising Signs Near Freeways Traffic Hazards?" Traffic. Engineer, 26 (1955), Pp. 71-76.

Versace, J. "Factor Analysis of Roadway and Accident Data." Highway Research Board Bulletin, 240 (1960), pp. 24-30.

Winkel, G., R. Malek and P. Thiel. "Community Response to the Design Features of Roads: A Technique for Measurement." Highway Research Record, 305 (1970), pp. 133-145. 
BIOGRAPHICAL SKETCH

C. Josh Holahan is an Assistant Professor in the Department of Psychology and an Associate Director of the Community Psychology Training Program at The University of Texas at Austin. He received his educational training at Duquesne University in Pittsburgh, Pennsylvania (B.A., 1967), the University of Massachusetts in Amherst (M.S., 1970; Ph.D., 1971), and the City University of New York (post-doctora1, 1973).

Holahan has done extensive research, authored several articles and has participated in a number of conferences in psychology-related areas.

His special interests lie in the areas of Environmental and Community Psychology, with particular interest in the coping mechanisms humans utilize in dealing with their complex built and social environment. 


\section{RESEARCH MEMORANDA PUBLISHED BY THE COUNCIL FOR ADVANCED TRANSPORTATION STUDIES}

1 Human Response in the Evaluation of Modal Choice Decisions. C. Shane Davies, Mark Alpert, and W. Ronald Hudson, April 1973.

2 Access to Essential Services. Ronald Briggs, Charlotte Clark, James Fitzsimmons, and Paul Jensen, April 1973.

3 Psychological and Physiological Responses to Stimulation. D. W. Wooldridge, A. J. Healey, and R. O. Stearman, August 1973.

4 An Intermodal Transportation System for the Southwest: A Preliminary Proposal. Charles P. Zlatkovich, September 1973.

5 Passenger Travel Patterns and Mode Selection. Shane Davies, Mark Alpert, Harry Wolfe, and Rebecca Gonzalez, October 1973.

6 Segmenting a Transportation Market by Determinant Attributes of Modal Choice. Shane Davies and Mark Alpert, October 1973.

7 The Interstate Rail System: A Proposal. Charles P. Zlatkovich, December 1973.

8 Literature Survey on Passenger and Seat Modeling for the Evaluation of Ride Quality. Bruce Shanahan, Ronald Stearman, and Anthony Healey, November 1973.

9 The Definition of Essential Services and the Identification of Key Problem Areas. Ronald Briggs and James Fitzsimmons, January 1974.

10 A Procedure for Calculating Great Circle Distances Between Ceographic Locations. J. Bryan Adair, March 1974.

11 MAPRINT: A Computer Program for Analyzing Changing Locations of Non-Residential Activities. Graham Hunter, Richard Dodge, and C. Michael Walton, March 1974.

12 A Method for Assessing the Impact of the Energy Crisis on Highway Accidents in Texas. E. L. Frome and C. Michael Waiton, February 1975.

13 State Regulation of Air Transportation in Texas. Robert C. Means and Barry Chasnoff, April 1974.

14 Transportation Atlas of the Southwest. Charles P. Zlatkovich, S. Michael Dildine, Eugene Robinson, James W. Wilson, and I. Bryan Adair, June 1974.

15 Local Covernmental Decisions and Land-Use Change: An Introductory Bibliography. W. D. Chipman, May 1974.

16 An Analysis of the Truck Inventory and Use Survey Data for the West South Central States. Michael Dildine, July 1974.

17 Towards Estimating the Impact of the Dallas-Fort Worth Regional Airport on Ground Transportation. William I. Dunlay and Lyndon Henry, September 1974.

18 The Attainment of Riding Comfort for a Tracked Air-Cushion Vehicle Through the Use of an Active Aerodynamic Suspension. Bruce Shanahan, Ronald Stearman, and Anthony Healey, September 1974.

19 Legal Obstacles to the Use of Texas School Buses for Public Transportation. Robert Means, Ronald Briggs, John E. Nelson, and Alan J. Thiemann, January 1975.

20 Pupil Transportation: A Cost Analysis and Predictive Model. Ronald Briggs and David Venhuizen, April 1975.

21 Variables in Rural Plant Location: A Case Study of Sealy, Texas. Ronald Linehan, C. Michael Walton, and Richard Dodge, February 1975.

22 A Description of the Application of Factor Analysis to Land Use Change in Metropolitan Areas. John Sparks, Carl Gregory, and Jose Montemayor, December 1974.

23 A Forecast of Air Cargo Originations in Texas to 1990. Mary Lee Metzger Gorse, November 1974.

24 A Systems Analysis Procedure for Estimating the Capacity of an Airport: A Selected Bibliography. Chang-Ho Park, Edward V. Chambers, III, and William J. Dunlay, Jr., August 1975.

25 System 2000-Data Management for Transportation Impact Studies. Gordon Derr, Richard Dodge, and C. Michael Walton, September 1975.

26 Regional and Community Transportation Planning Issues: A Selected Bibliography. John Huddleston, Ronald Linehan, Abdulla Sayyari, Richard Dodge, C. Michael Walton, and Marsha Hamby, September 1975.

27 A Systems Analysis Procedure for Estimating the Capacity of an Airport: System Definition, Capacity Definition, and Review of Available Models. Edward V. Chambers, III, Tommy Chmores, William J. Dunlay, Ir., Nicolau D. F. Gualda, B. F. McCullough, ChangHo Park, and John Zaniewski, October 1975.

28 The Application of Factor Analysis to Land Use Change in a Metropolitan Area. John Sparks and Jose Montemayor, November 1975.

29 Current Status of Motor Vehicle Inspection: A Survey of Available Literature and Information. John Walter Ehrfurth and David A. Sands, December 1975.

30 Executive Summary: Short Range Transit Improvement Study for The University of Texas at Austin. C. Michael Walton, May 1976 31 A Preliminary Analysis of the Effects of the Dallas-Fort Worth Regional Airport on Surface Transportation and Land Use. Harry Wolfe, April 1974.

32 A Consideration of the Impact of Motor Common Carrier Service on the Development of Rural Central Texas. James Wilson, February 1975.

33 Modal Choice and the Value of Passenger Travel Time Literature: A Selective Bibliography. Shane Davies and Mark I. Alpert, March 1975.

34 Forecast of Air Cargo Originations in Arkansas, Louisiana, and Oklahoma to 1990. Deborah Goltra, April 1975.

35 Inventory of Freight Transportation in the Southwest/Part IV: Rail Service in the Dallas-Fort Worth Area. Charles P. Zlatkovich, Mary L. Gorse, Edward N. Kasparik, and Dianne Y. Priddy, April 1975.

36 Forecast of Waterborne Commerce Handled by Texas Ports to 1990. Stuart Metz Dudley, April 1975.

37 Forecast of Refinery Receipts of Domestic Crude Oil from Pipelines in the West South Central States to 1990. Mary L. Gorse, Dianne Y. Priddy, and Deborah J. Goltra, April 1975.

38 A Feasibility Study of Rail Piggyback Service Between Dallas-Fort Worth and San Antonio. Edward N. Kasparik, April 1975.

39 Land Value Modeling in Rural Communities. Lidvard Skorpa, Richard Dodge, and C. Michael Walton, June 1974.

40 Toward Computer Simulation of Political Models of Urban Land Use Change. Carl Gregory, August 1975.

41 A Multivariate Analysis of Transportation Improvements and Manufacturing Growth in a Rural Region. Ronald Linehan, C. Michael Walton, and Richard Dodge, October 1975.

42 A Transit Demand Model for Medium-Sized Cities. John Shortreed, December 1975. 


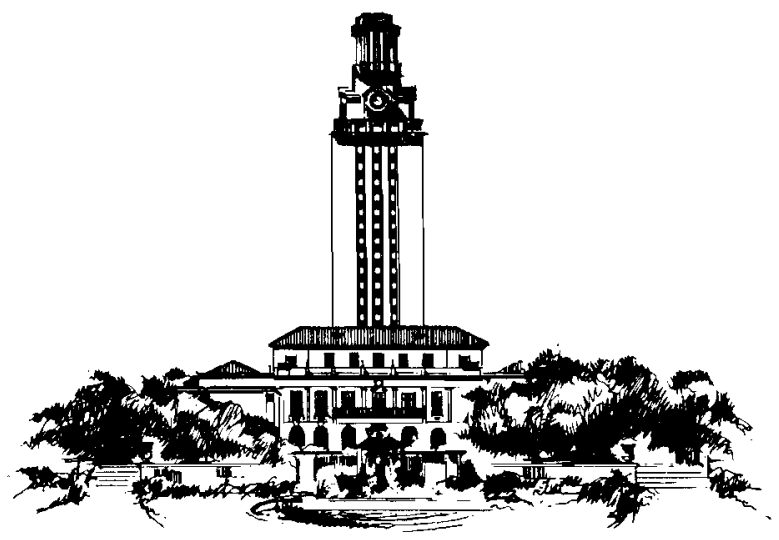

Council for Advanced Transportation Studies

THE UNIVERSITY OF TEXAS AT AUSTIN 